\title{
Influences of Diamines on the Morphologies and the Chemical, Thermal, and Mechanical Properties of Polyurethane-Imide Elastomers
}

\author{
Tomohiro Ueda ${ }^{1}$, Tomohiro Nishio ${ }^{2}$, Shinichi Inoue ${ }^{1}$ \\ ${ }^{1}$ Department of Applied Chemistry, Aichi Institute of Technology, Toyota, Japan \\ ${ }^{2}$ Technical Center, Department of Product Development, Nitta Corporation Ltd., Yamatokohriyama, Japan \\ Email:w15801ww@aitech.ac.jp
}

How to cite this paper: Ueda, T., Nishio, T. and Inoue, S. (2017) Influences of Diamines on the Morphologies and the Chemical, Thermal, and Mechanical Properties of Polyurethane-Imide Elastomers. Open Journal of Organic Polymer Materials, 7, 47-60. https://doi.org/10.4236/ojopm.2017.74004

Received: September 13, 2017

Accepted: October 16, 2017

Published: October 19, 2017

Copyright () 2017 by authors and Scientific Research Publishing Inc. This work is licensed under the Creative Commons Attribution International License (CC BY 4.0).

http://creativecommons.org/licenses/by/4.0/

\begin{abstract}
Polyurethane-imide elastomers (PUIEs) are formed from isocyanate, polyol, acid anhydride, and diamine by liquid polymerization. Unfortunately, many of the diamines have rarely been applied to the formation of PUIEs. Hence, investigating the effect of diamines on PUIEs remains a challenge in polymer chemistry. Herein, PUIEs prepared from 4,4'-diphenylmethane diisocyanate (MDI), polytetramethylene glycol (Mw: 1000), pyromellitic dianhydride, and aromatic diamines (such as $p$-phenylene diamine, 4,4'-oxydianiline, and 1,3-bis(4-aminophenoxy)benzene), and aliphatic diamines (such as 1,2-ethylene diamine, 1,6-hexamethylene diamine, and 1,12-dodecamethylene diamine) were synthesized by liquid polymerization. The morphologies and the chemical, thermal, and mechanical properties of the various PUIEs were investigated. The obtained elastomeric sheets were characterized in terms of the following tests and methods: solubility and swelling tests, X-ray diffraction and differential scanning calorimetry, dynamic mechanical analysis and thermogravimetric analysis, tensile tests, nuclear magnetic resonance spectroscopy, infrared spectroscopy, atomic force microscopy, contact angle microscopy, and scanning electron microscopy.
\end{abstract}

\section{Keywords}

Polyurethane-Imide, Diisocyanate, Polyol, Diamine, Pyromellitic

Dianhydride, Solution Polymerization

\section{Introduction}

Polyurethane (PU) is easily synthesized from isocyanates and polyols by the po- 
lyaddition reaction. Hence, PU has been widely used in a variety of applications in many different fields. PU can be synthesized with customized specifications for rubber elasticity, abrasion resistance, and adhesion. In general, PU has a basic problem in terms of heat resistance. However, by improving this fundamental property, PU may gain some industrial advantages. Therefore, chemists have actively conducted multiple studies on the heat resistance of PU. Polyurethane-imide (PUI), which has stability in high-temperature environments, excellent electrical and mechanical properties, and good chemical resistance, is prepared via an organic-organic hybrid between urethane and imide [1]-[8]. PUI possesses some distinctive properties such as heat resistance and solvent resistance. Therefore, PUI has found special applications in some industries and continues to gain importance in a variety of applications. PUI is used in a surprising array of commercial applications. For convenience, PUI is classified into three major types of products: foams [9] [10], elastomers [11] [12] [13] [14], and resins [15] [16] [17]. On the basis of such a background, we focused on a novel heat-resistant elastomer that is widely used for commercial products. As we attempted to improve the synthetic method of PUI elastomers (PUIEs), we were successful in the improvement of synthetic method [2] [6]. Thus, we focused on diamines as raw materials. Although various diamines are utilized in the field of polyimide (PI) formation, they are not considerably used in the field of PUIEs. Therefore, from both theoretical and practical standpoints, it is important to synthesize PUIEs using various diamines. To allow various diamines to be widely applied, retaining elastic property of PUIEs becomes a key factor. Herein, the following materials are used for the synthesis of PUIEs: 4,4'-diphenylmethane diisocyanate, polytetramethylene glycol (Mw: 1000), aromatic diamines (p-phenylenediamine, 4,4'oxydianiline, and 1,3-bis(4-amino-phenoxy)benzene), aliphatic diamines (1,2-ethylene diamine, 1,6-hexamethylene diamine, and 1,12-dodecamethylene diamine), and pyromellitic dianhydride. The morphologies, chemical properties, and physical properties of the synthesized PUIEs were examined to investigate the effect of diamines on PUIEs.

\section{Experimental}

\subsection{Materials}

Polytetramethylene glycol (Mw: 1000) (PTMG1000) was supplied by Invista Industry, Texas, USA. PTMG1000 was dehydrated in vacuo at $80^{\circ} \mathrm{C}$ for $24 \mathrm{~h}$ before use. 4,4'Diphenylmethane diisocyanate (MDI) was supplied by Tosoh Industry, Tokyo, Japan. MDI was purified by distillation under reduced pressure (267 $400 \mathrm{~Pa}$ ) at $135^{\circ} \mathrm{C}$ before use. Pyromellitic dianhydride (PMDA) was purchased from Nacalai Tesque, Inc., Kyoto, Japan (Nacalai), and used without further purification. The following compounds were purchased from Tokyo Chemical Industry (TCI), Tokyo, Japan: ethylene diamine (EDA); 4,4'-oxydianiline (ODA); 1,3-bis(4-aminophenoxy)benzene (BAPB); and 1,12-dodecame-thylene diamine (DMDA). EDA was purified by distillation (trap to trap) under reduced pressure (267 - $400 \mathrm{~Pa}$ ) before use. $p$-Phenylene diamine (PPDA) and 1,6-hexamethylene 
diamine (HMDA) were purchased from Kanto Chemical, Tokyo, Japan. PPDA was recrystallized from toluene before use. Tetrahydrofuran (THF) and benzene were purchased from Nacalai and distilled over calcium hydride in an Ar atmosphere. $N, N$-Dimethyl formamide (DMF) and dimethyl sulfoxide (DMSO) were purchased from Nacalai and stored over $4 \AA$ molecular sieves before use. The following compounds were purchased from commercial suppliers and used as received: hexane (Nacalai), and acetone (Nacalai). $\mathrm{N}$-methyl-2-pyrrolidone (NMP) (Nacalai) was kept over a $4 \AA$ molecular sieve. Methanol was supplied by Toyota Kagaku Kogyo Co. Ltd., Toyota, Japan.

\subsection{Synthesis}

Scheme 1 shows the procedure for PUIE preparation. The PUIE compositions are listed in Table 1. PUIEs were prepared by liquid polymerization. In a $100 \mathrm{~mL}$ four-necked separable reaction flask equipped with a mechanical stirrer, a gas inlet tube, and a reflux condenser, MDI, PTMG1000, and NMP (10 mL) were placed, and the mixture was stirred at $80^{\circ} \mathrm{C}$ for $30 \mathrm{~min}$. A solution of PMDA in NMP $(15 \mathrm{~mL})$ was added to this reaction mixture, and the mixture was stirred at $150^{\circ} \mathrm{C}$ for $15 \mathrm{~min}$. Solutions of diamines in NMP $(10 \mathrm{~mL})$ (aromatic amine) or $(20 \mathrm{~mL})$ (aliphatic amine) were added, and the mixtures were stirred at $150^{\circ} \mathrm{C}$ for $2 \mathrm{~h}$. Then, NMP ( $5 \mathrm{~mL}$ ) (aromatic amine) or $(10 \mathrm{~mL})$ (aliphatic amine) was added. The reactions proceeded under an Ar atmosphere. Test sheets were prepared by casting half of the obtained solution using a centrifugal casting machine at $150^{\circ} \mathrm{C}$ for $24 \mathrm{~h}$, after which the sheets were treated at $200^{\circ} \mathrm{C}$ for $4 \mathrm{~h}$ in vacuo.

\subsection{Characterization}

\subsubsection{Nuclear Magnetic Resonance (NMR) Spectroscopy}

NMR spectra were recorded on a Bruker (Massachusetts, USA) AVANCE III HD $400\left({ }^{13} \mathrm{C}, 75.4 \mathrm{MHz}\right)$ NMR spectrometer using the ${ }^{13} \mathrm{C}$ CP/MAS method.

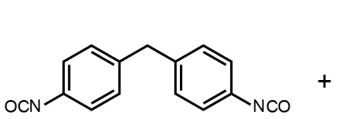

MDI

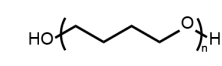

PTMG1000

Mixing: $80^{\circ} \mathrm{C}, 30 \mathrm{~min}$ in NMP, under $\mathrm{Ar}$<smiles>O=c1oc(=O)c2cc3c(=O)oc(=O)c3cc12</smiles>

NMP $(15 \mathrm{~mL})$ Mixing: $150^{\circ} \mathrm{C}, 15$ min, under $\mathrm{Ar}$

Diamine

2) in NMP (aliphatic diamine : $20 \mathrm{~mL}$

3) Mixing: $150^{\circ} \mathrm{C}, 2 \mathrm{~h}$, under $\mathrm{Ar}$

1) Casting: $150^{\circ} \mathrm{C}, 24 \mathrm{~h}$ 2) Imidization: $200^{\circ} \mathrm{C}, 4 \mathrm{~h}$, in vacuo

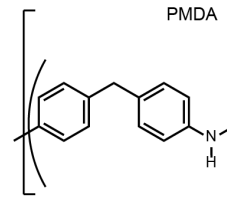

MDA

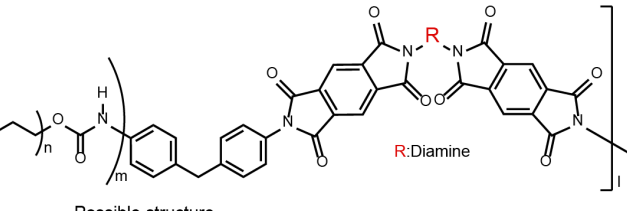

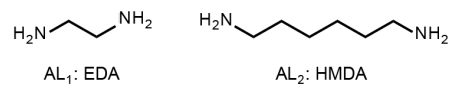

$\mathrm{H}_{2} \mathrm{~N}$

$\mathrm{AL}_{3}$ : DMDA

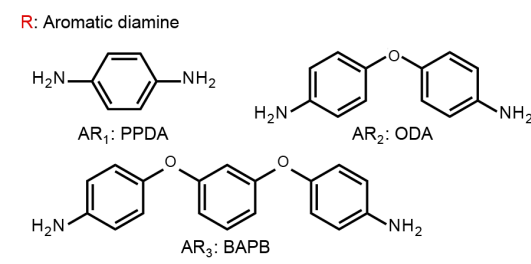

R: Aromatic diamine 
Table 1. Compositions of the PUIEs synthesized in this study.

\begin{tabular}{|c|c|c|c|c|}
\hline Sample & $\begin{array}{c}\mathrm{MDI}^{\mathrm{a}} \\
\left(\times 10^{-3} \mathrm{~mol}\right)\end{array}$ & $\begin{array}{l}\text { PTMG1000 } \\
\left(\times 10^{-3} \mathrm{~mol}\right)\end{array}$ & $\begin{array}{l}\text { Diamine } \\
\left(\times 10^{-3} \mathrm{~mol}\right)\end{array}$ & $\begin{array}{c}\mathrm{PMDA}^{\mathrm{d}} \\
\left(\times 10^{-3} \mathrm{~mol}\right)\end{array}$ \\
\hline PUIE-AL ${ }_{1}$ & 4.71 & 2.50 & 2.25 & 4.50 \\
\hline PUIE-AL ${ }_{2}$ & 4.60 & 2.50 & 2.08 & 4.20 \\
\hline PUIE- $\mathrm{AL}_{3}$ & 4.40 & 2.50 & 1.90 & 3.80 \\
\hline PUIE-AR $_{1}$ & 4.64 & 2.50 & 2.11 & 4.23 \\
\hline PUIE-AR ${ }_{2}$ & 4.40 & 2.50 & 1.90 & 3.80 \\
\hline PUIE-AR ${ }_{3}$ & 4.24 & 2.50 & 1.72 & 3.42 \\
\hline
\end{tabular}

${ }^{\mathrm{a}} \mathrm{MDI}: \mathrm{Mw}=250.25$; ${ }^{\mathrm{b}} \mathrm{PTMG1000}: \mathrm{Mw}=1000$; ${ }^{\mathrm{C}}$ Diamines: $\mathrm{AL}_{1}=$ ethylene diamine $(\mathrm{EDA}) \mathrm{Mw}=60.1, \mathrm{AL}_{2}=$ 1,6-hexamethylene diamine (HMDA), $\mathrm{Mw}=116.21, \mathrm{AL}_{3}=1,12$-dodecamethylene diamine (DMDA) $\mathrm{Mw}=$ 200.37, $\mathrm{AR}_{1}=p$-phenylene diamine $(\mathrm{PPDA}), \mathrm{Mw}=108.14, \mathrm{AR}_{2}=4,4^{\prime}$-oxydianiline (ODA) $\mathrm{Mw}=200.24$, $\mathrm{AR}_{3}=1,3$-bis(4-amino-phenoxy)benzene (BAPB) $\mathrm{Mw}=292.34$; ${ }^{\mathrm{d}} \mathrm{PMDA}: \mathrm{Mw}=218.12$.

\subsubsection{Fourier Transform Infrared (FTIR) Spectroscopy}

FTIR spectra were recorded on a JASCO (Tokyo, Japan) FTIR-5300 spectrometer equipped with an attenuated total reflection (ATR) system, which used an ATR500/M with ATR prism KRS-5.

\subsubsection{X-Ray Diffraction (XRD) Analyses}

XRD patterns were measured from $5^{\circ}$ to $50^{\circ}$ ( $2 \theta$ value) with $\mathrm{Cu} \mathrm{K}$ (conditions: $\lambda$ $=0.154 \mathrm{~nm}, 40 \mathrm{kV}, 100 \mathrm{~mA}$ ) on a Rigaku (Tokyo, Japan) RINT $2500 \mathrm{~V} / \mathrm{PC}$.

\subsubsection{Morphological Analyses}

Scanning Electron Microscopy (SEM) was used to observe the surface morphology of PUIEs using a JEOL (Tokyo, Japan) JSM-6335 FM. All micrographs were taken at a magnification of $30 \mathrm{k} \times$.

Atomic force microscopy (AFM) measurements were performed on dried sheets at room temperature in air using an OLYMPUS (Tokyo, Japan) NV2000. Most of the images were obtained in tapping-mode (ACAFM) with a silicon nitride cantilever (OMMCL-AC 240TS-C2; Olympus optical) using a spring constant of $15 \mathrm{~N} / \mathrm{m}$ and a resonating frequency of $20 \mathrm{KHz}$. The scanning rates varied from 1 to $2 \mathrm{~Hz}$. All images presented here were reproduced from images obtained for at least three points on each sample surface.

Contact angle (CA) measurements were performed on dried sheets at room temperature $\left(23^{\circ} \mathrm{C} \pm 2^{\circ} \mathrm{C}\right)$ in air using an Excimer Inc. (Yokohama, Japan) Simage Standard 100 instrument. Samples were dripped of $5 \mu \mathrm{L}$.

\subsubsection{Chemical Properties}

Swelling tests were performed using $0.1000 \mathrm{~g}$ test pieces. The degree of swelling (Rs) was calculated using the formula $\mathrm{Rs}(\%)=\mathrm{W}^{\prime}-\mathrm{W} / \mathrm{W} \times 100$, where $\mathrm{W}^{\prime}$ is the weight of the test piece soaked in benzene for $24 \mathrm{~h}$ and $\mathrm{W}$ is the weight of the test piece after drying at $30^{\circ} \mathrm{C}$ for $24 \mathrm{~h}$ in vacuo.

Solubility tests were performed using $0.1000 \mathrm{~g}$ test pieces. Each test piece was soaked in a solvent (methanol, benzene, hexane, acetone, THF, DMF, DMSO, or $\mathrm{NMP} ; 30.0 \mathrm{~mL}$ ) at room temperature for $24 \mathrm{~h}$. 


\subsubsection{Mechanical Properties}

Hardness tests were performed using a KOUBUNSHI KEIKI (Kyoto, Japan) Asker durometer (type A durometer (shore A)) with test pieces stacked to achieve a thickness of $6 \mathrm{~mm}$.

Tensile tests were performed on an ORIENTEC (Tokyo, Japan) RTC-1225A Universal Tensile Testing Instruments equipped with model-U-4300 extensometer using a JIS K 6251-3-dumbbell as the standard sample and a crosshead speed of $100 \mathrm{~mm} / \mathrm{min}$.

\subsubsection{Thermal Properties}

Differential scanning calorimetry (DSC) measurements were performed on a Rigaku (Tokyo, Japan) Thermo-Plus DSC-8230 instrument at $10^{\circ} \mathrm{C} / \mathrm{min}$ from $-120^{\circ} \mathrm{C}$ to $200^{\circ} \mathrm{C}$ under an $\mathrm{Ar}$ atmosphere. Approximately $5.0 \mathrm{mg}$ of each PUIE was weighed and sealed in an aluminum pan. The samples were rapidly cooled to $-120^{\circ} \mathrm{C}$ and then heated to $200^{\circ} \mathrm{C}$ at $10^{\circ} \mathrm{C} / \mathrm{min}$.

Dynamic mechanical analyses (DMA) were performed on a Seiko Instruments (Chiba, Japan) DMS 6100 instrument at $5^{\circ} \mathrm{C} / \mathrm{min}$ from $-100^{\circ} \mathrm{C}$ to $300^{\circ} \mathrm{C}$ at 20 $\mathrm{Hz}$ under an $\mathrm{N}_{2}$ atmosphere.

Thermogravimetric analyses (TGA) were performed on a Seiko Instruments TG/DTA6200 instrument (Chiba, Japan) at a heating rate of $10^{\circ} \mathrm{C} / \mathrm{min}$ from $30^{\circ} \mathrm{C}$ to $500^{\circ} \mathrm{C}$ under an $\mathrm{N}_{2}$ atmosphere.

\section{Results and Discussion}

\subsection{NMR Studies}

${ }^{13} \mathrm{C}$ NMR spectra of the PUIEs were measured using the solid-state method. The ${ }^{13} \mathrm{C}$ CP/MAS NMR spectrum of PUIE- $\mathrm{AR}_{2}$ is shown in Figure 1. Urethane carbon peaks at $153.5(\mathrm{n}), 70.6$ (c), 41.7 (b), and 26.8 (a) ppm and an imide carbon peak at $164.4 \mathrm{ppm}$ are observed. The diamine (ODA) peaks at $115.4-141.6 \mathrm{ppm}$ (e, $\mathrm{d}, \mathrm{l}$, and $\mathrm{m}$ ) are also observed.

\subsection{FTIR Studies}

The FTIR spectra (ATR method) of the PUIEs are shown in Figure 2. The peaks are observed for PUIEs at around 3300 and $1720 \mathrm{~cm}^{-1}(\mathrm{~N}-\mathrm{H}$ stretching and $\mathrm{C}=\mathrm{O}$ stretching of urethane, respectively), at around $3080 \mathrm{~cm}^{-1}$ (aromatic C-H stretching of urethane), and at around 2940, 2852, and $2794 \mathrm{~cm}^{-1}$ (aliphatic C-H stretching of urethane). In addition, the peaks at around $1773 \mathrm{~cm}^{-1}, 1725 \mathrm{~cm}^{-1}$, and $1375 \mathrm{~cm}^{-1}$ ( $\mathrm{C}=\mathrm{O}$ stretching and $\mathrm{C}-\mathrm{N}$ stretching of imide, respectively) in the spectra of the PUIEs indicate that almost all of the $\mathrm{N}-\mathrm{H}$ and $\mathrm{C}=\mathrm{O}$ are hydrogen bonded. Furthermore, the peak at around $1093 \mathrm{~cm}^{-1}$ (C-O-C stretching of urethane) is observed.

\subsection{XRD Analyses}

The XRD patterns of the PUIEs are illustrated in Figure 3. Broad diffraction peaks, which were mainly attributed to the amorphous nature of the PUIEs with 


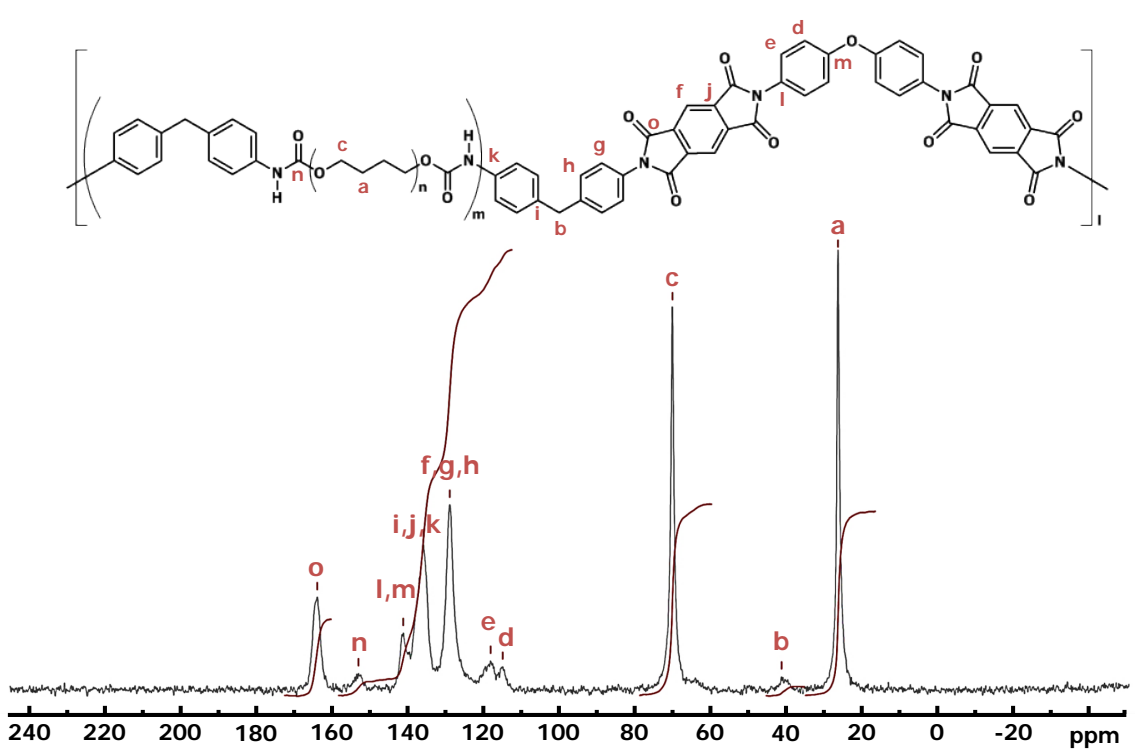

Figure 1. The solid-state ${ }^{13} \mathrm{C} \mathrm{CP} / \mathrm{TOSS}$ nuclear magnetic resonance (NMR) spectrum of the PUIE- $\mathrm{AR}_{2}$.

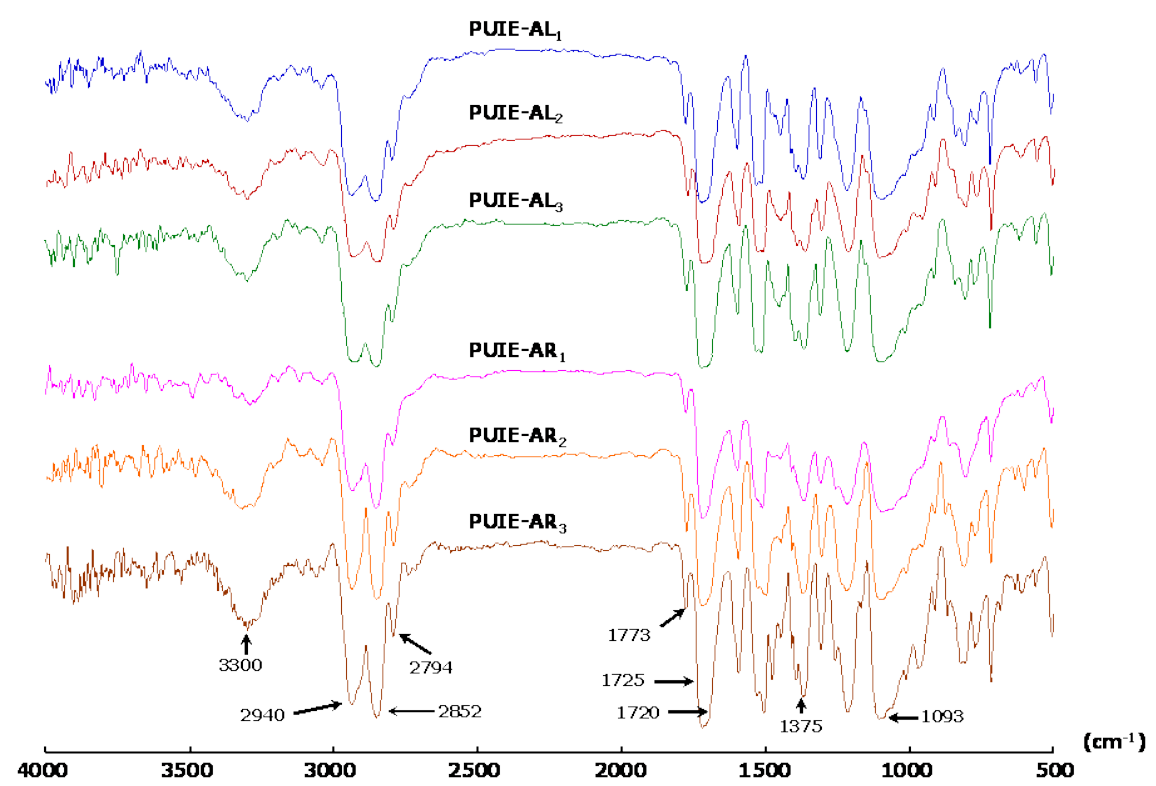

Figure 2. Fourier transform infrared (FTIR) spectra of PUIEs: blue (PUIE- $\mathrm{AL}_{1}$ ), red $\left(\mathrm{PUIE}-\mathrm{AL}_{2}\right)$, green $\left(\mathrm{PUIE}-\mathrm{AL}_{3}\right)$, pink $\left(\mathrm{PUIE}-\mathrm{AR}_{1}\right)$, orange $\left(\mathrm{PUIE}-\mathrm{AR}_{2}\right)$, and brown $\left(\mathrm{PUIE}-\mathrm{AR}_{3}\right)$.

aromatic diamines, were observed at around $20^{\circ}$. However, broad diffraction peaks of the PUIEs with aliphatic diamines (PUIE- $\mathrm{AL}_{2}$ and PUIE- $\mathrm{AL}_{3}$ ) were not observed.

\subsection{Morphological Analyses}

Generally speaking, molecular angles are smaller on smooth surfaces than on rough surfaces. In order to understand the distinction between the PUIEs with 


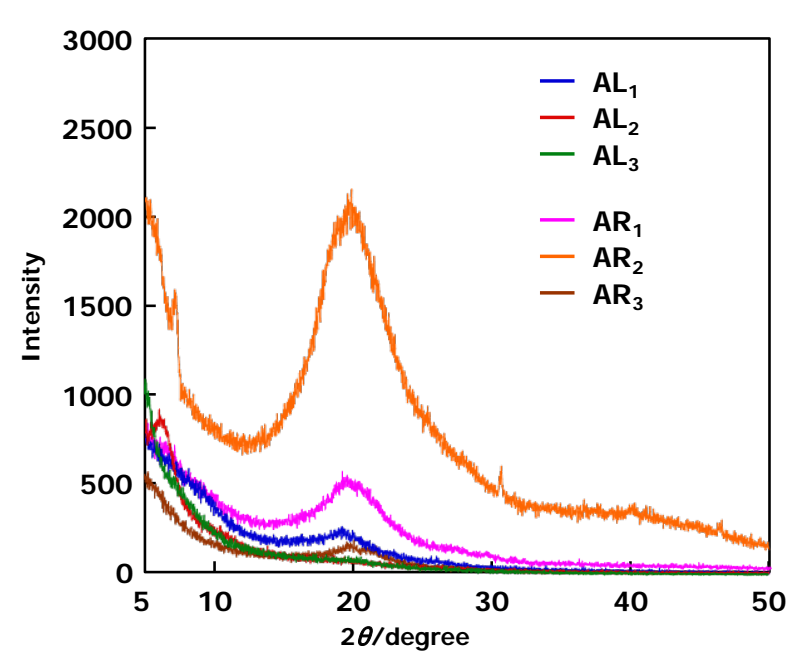

Figure 3. X-ray diffraction (XRD) patterns of PUIEs: blue (PUIE- $\left.\mathrm{AL}_{1}\right)$, red $\left(P U I E-A_{2}\right)$, green (PUIE- $\left.\mathrm{AL}_{3}\right)$, pink (PUIE- $\left.A R_{1}\right)$, orange $\left(\mathrm{PUIE}-\mathrm{AR}_{2}\right.$ ), and brown (PUIE- $\left.\mathrm{AR}_{3}\right)$.

various diamine components, it was necessary to observe and investigate the surface wettability of the PUIE sheets. The contact angles of water on the surface of PUIE sheets were measured at room temperature and atmospheric pressure. Figure 4 shows the contact angles of PUIE sheets with the various diamines. The contact angle values of the PUIE sheets with an aliphatic diamine were nearly identical and indicated hydrophobicity. However, the contact angles of the PUIE sheets with aromatic diamines decreased as the molecular length of diamine increased, i.e., the hydrophobicity of the PUIE sheets decreased gradually.

The surface topographies of the PUIEs were examined by AFM (Figure 5) over a $2 \times 2 \mu \mathrm{m}^{2}$ scan area. AFM was utilized to study the phase-segregated morphology of the PUIEs with various hard segment structures. Topographical heterogeneities were observed in the PUIEs, which may reflect the existence of ordering tendencies in the polymer structure. In these images, by convention, the hard and soft segments appear as bright and dark regions, respectively. By increasing the molecular length of the diamine, changes were observed in the surface morphology. The AFM image of short-molecular-length diamine-containing PUIE has an extended smoother surface area in comparison with long-molecular-length diamine-containing PUIE. The hard domains (bright spots) are grouped into compact areas and appear as thick regions. The hard segment agglomerates can be seen in limited areas that benefit from a better ordering.

SEM micrographs of the PUIE surfaces are depicted in Figure 6. PUIEs with short-molecular-length diamines show a rougher surface than PUIEs with longer-molecular-length diamines, and the phase separation is not very clear owing to the fewer agglomerates of hard domains. The size of the lighter parts, which are the hard domains, is approximately $1-3 \mu \mathrm{m}$, and the area covered is larger for the short-molecular-length diamine-containing PUIEs than the 


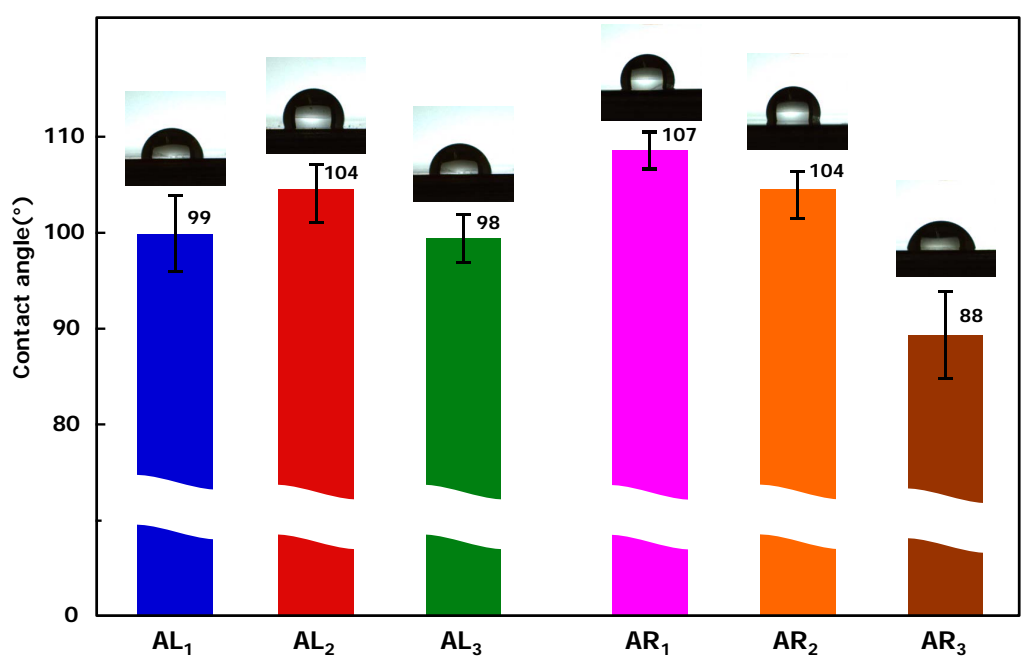

Figure 4. Visual performance of the water droplet contact angles on the different PUIE sheets: blue $\left(A L_{1}\right)$, red $\left(A L_{2}\right)$, green $\left(A L_{3}\right)$, pink $\left(A R_{1}\right)$, orange $\left(\mathrm{AR}_{2}\right)$, and brown $\left(\mathrm{AR}_{3}\right)$.

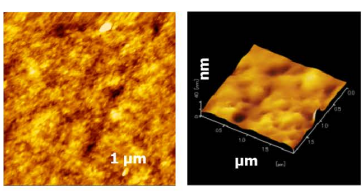

PUIE-AL

(a)

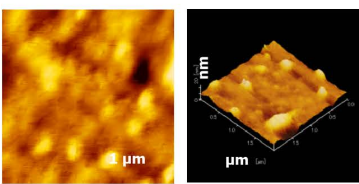

PUIE-AR

(d)

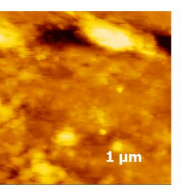

PUIE-AL 2

(b)

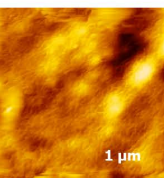

PUIE-AR

(e)
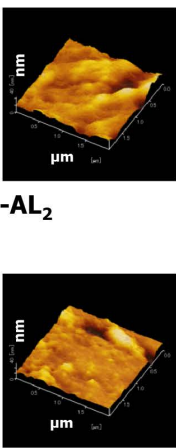

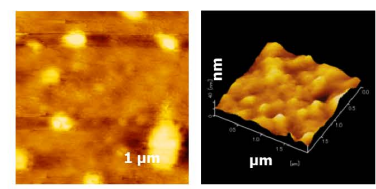

PUIE-AL 3

(c)

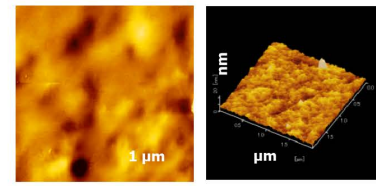

PUIE-AR

(f)

Figure 5. Topographic and three-dimensional atomic force microscopy (AFM) images of PUIEs: (a) PUIE-AL ; $_{1}$ (b) PUIE-AL ; $_{2}$ (c) PUIE-AL ${ }_{3}$; (d) PUIE-AR F $_{1}$ (e) PUIE-AR ; and (f) PUIE-AR .

long-molecular-length diamine-containing PUIEs. This may be caused by the increase in compatibility between the hard segments and soft segments. These phase separations are quite different from that of PU. The hard domains are considered to correspond to the imide portions and are in agreement with the AFM results.

\subsection{Chemical Properties}

The solvent resistances of PUIEs were tested by immersing each of the PUIE sheets in various solvents, such as benzene, hexane, THF, acetone, methanol, DMF, DMSO, and NMP. The results are presented in Table 2. None of the PUIEs dissolved in benzene, hexane, THF, acetone, methanol, DMF, and DMSO at room temperature $\left(23^{\circ} \mathrm{C} \pm 2{ }^{\circ} \mathrm{C}\right)$. However, in NMP at room temperature, PUIE- $\mathrm{AL}_{1}$ completely dissolved and PUIE- $\mathrm{AL}_{2}, \mathrm{PUIE}-\mathrm{AL}_{3}, \mathrm{PUIE}-\mathrm{AR}_{1}$, and 


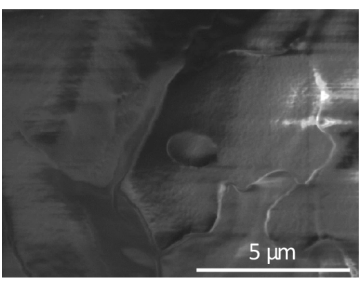

PUIE-AL $\mathbf{L}_{1}$

(a)

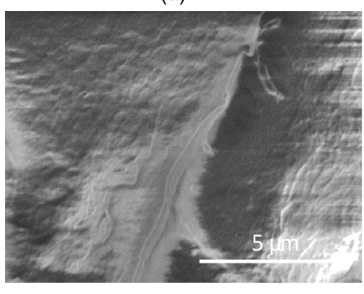

PUIE-AR

(d)

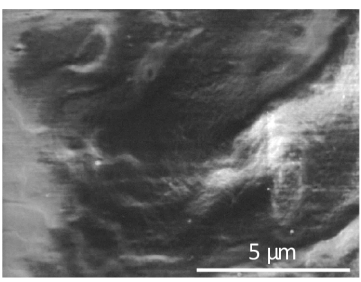

PUIE- $\mathbf{A L}_{2}$

(b)

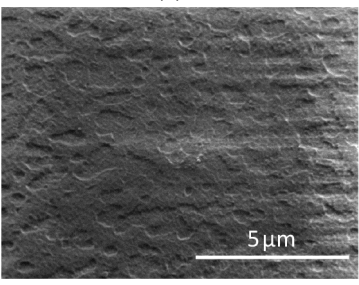

PUIE-AR 2

(e)

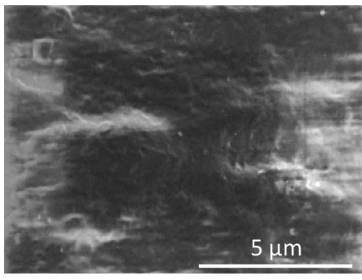

PUIE-AL

(c)

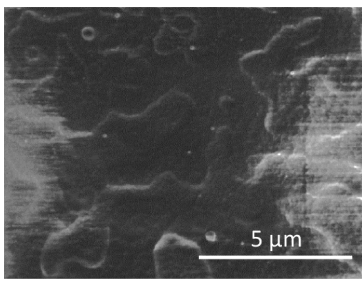

PUIE_AR 3

(f)

Figure 6. Scanning electron microscopies of PUIEs: (a) PUIE- $\mathrm{AL}_{1}$; (b) PUIE- $\mathrm{AL}_{2}$; (c) PUIE-AL ${ }_{3}$; (d) PUIE-AR $;$; (e) PUIE-AR ${ }_{2}$; and (f) PUIE-AR .

Table 2. Solubility tests of the PUIEs ${ }^{\mathrm{a}}$.

\begin{tabular}{ccccccccc}
\hline Sample & Benzene & Hexane & THF & Acetone & Methanol & DMF & DMSO & NMP \\
\hline PUIE-AL & $\times$ & $\times$ & $\times$ & $\times$ & $\times$ & $\times$ & $\times$ & $\bigcirc$ \\
PUIE-AL & $\times$ & $\times$ & $\times$ & $\times$ & $\times$ & $\times$ & $\times$ & $\Delta$ \\
PUIE-AL $_{3}$ & $\times$ & $\times$ & $\times$ & $\times$ & $\times$ & $\times$ & $\times$ & $\Delta$ \\
PUIE-AR $_{1}$ & $\times$ & $\times$ & $\times$ & $\times$ & $\times$ & $\times$ & $\times$ & $\Delta$ \\
PUIE-AR $_{2}$ & $\times$ & $\times$ & $\times$ & $\times$ & $\times$ & $\times$ & $\times$ & $\Delta$ \\
PUIE-AR & $\times$ & $\times$ & $\times$ & $\times$ & $\times$ & $\times$ & $\times$ & $\times$ \\
\hline
\end{tabular}

O: completely dissolved; $\Delta$ : slightly dissolved; $\mathbf{x}$ : undissolved; ${ }^{a}$ Measurement conditions: benzene, hexane, acetone, THF, NMP, methanol, DMF, or DMSO as the solvent at room temperature $\left(23^{\circ} \mathrm{C} \pm 2^{\circ} \mathrm{C}\right)$.

PUIE- $\mathrm{AR}_{2}$ dissolved slightly. PUIE- $\mathrm{AR}_{3}$ did not dissolve in NMP at room temperature.

The swelling test results are summarized in Table 3. The swelling values for the PUIEs with aliphatic diamines were nearly identical (164\% - 166\%). However, the swelling values of PUIEs with aromatic diamines were lower than the swelling values for PUIEs with aliphatic diamines. Additionally, the swelling values for the PUIEs with aromatic diamines decreased as the molecular length of the diamine increased. This phenomenon might be a factor arising from the molecular packing density.

The hardness results of the PUIE sheets with different hard segment contents are also summarized in Table 3. The hardness of PUIEs with aliphatic diamines was lower than that of PUIEs with aromatic diamines. This corresponds with the swelling test results.

\subsection{Mechanical Properties}

Figure 7 shows the stress-strain curves for the PUIE sheets, and the corresponding tensile characteristic parameters are reported in Table 4. In Figure 7, 
Table 3. Physical properties of PUIEs.

\begin{tabular}{cccccc}
\hline Sample & $\begin{array}{c}\text { Hardness }^{\mathrm{a}} \\
\left(\text { Shore A) }^{2}\right.\end{array}$ & Swelling rate $^{\mathrm{b}}(\%)$ & $\operatorname{Tg}^{\mathrm{c}}\left({ }^{\circ} \mathrm{C}\right)$ & $\mathrm{T}_{5}{ }^{\mathrm{d}}\left({ }^{\circ} \mathrm{C}\right)$ & $\mathrm{T}_{50}{ }^{\mathrm{d}}\left({ }^{\circ} \mathrm{C}\right)$ \\
\hline PUIE-AL $_{1}$ & 75 & 164 & -45 & 351 & 431 \\
PUIE-AL $_{2}$ & 76 & 166 & -50 & 350 & 433 \\
PUIE-AL $_{3}$ & 76 & 165 & -45 & 356 & 435 \\
PUIE-AR $_{1}$ & 76 & 157 & -38 & 345 & 435 \\
PUIE-AR $_{2}$ & 81 & 154 & -57 & 351 & 437 \\
PUIE-AR $_{3}$ & 84 & 146 & -49 & 344 & 436 \\
\hline
\end{tabular}

${ }^{\mathrm{a}}$ Measurement conditions: shore A type, total thickness $=6 \mathrm{~mm}$, room temperature $\left(23^{\circ} \mathrm{C} \pm 2{ }^{\circ} \mathrm{C}\right) .{ }^{b} \mathrm{Mea}-$ surement conditions: benzene solvent at room temperature $\left(23^{\circ} \mathrm{C} \pm 2^{\circ} \mathrm{C}\right)$ for $24 \mathrm{~h}$. ${ }^{\circ} \mathrm{DSC}$ was performed at a heating rate of $10^{\circ} \mathrm{C} / \mathrm{min}$ from $-100^{\circ} \mathrm{C}$ to $300^{\circ} \mathrm{C}$ under an $\mathrm{Ar}$ atmosphere. ${ }^{\mathrm{d}} \mathrm{TGA}$ was performed at a heating rate of $10^{\circ} \mathrm{C} / \mathrm{min}$ from $30^{\circ} \mathrm{C}$ to $500^{\circ} \mathrm{C}$ under an $\mathrm{N}_{2}$ atmosphere.

Table 4. Tensile properties of the PUIEs with various diamines.

\begin{tabular}{ccccccccc}
\hline Sample & $\begin{array}{c}\sigma 10 \\
(\mathrm{MPa})\end{array}$ & $\begin{array}{c}\sigma 50 \\
(\mathrm{MPa})\end{array}$ & $\begin{array}{c}\sigma 100 \\
(\mathrm{MPa})\end{array}$ & $\begin{array}{c}\sigma 200 \\
(\mathrm{MPa})\end{array}$ & $\begin{array}{c}\sigma 300 \\
(\mathrm{MPa})\end{array}$ & $\begin{array}{c}\sigma 400 \\
(\mathrm{MPa})\end{array}$ & $\begin{array}{c}\sigma^{\mathrm{b}} \\
(\mathrm{MPa})\end{array}$ & $\begin{array}{c}\mathrm{Eb}^{\mathrm{c}} \\
(\%)\end{array}$ \\
\hline PUIE-AL $_{1}$ & 3.51 & 9.30 & 12.9 & 24.6 & 42.3 & - & 56.2 & 380 \\
PUIE-AL $_{2}$ & 3.52 & 7.46 & 10.0 & 17.4 & 35.9 & 68.0 & 63.9 & 406 \\
PUIE-AL $_{3}$ & 4.12 & 8.11 & 10.4 & 16.0 & 28.8 & 55.9 & 66.7 & 449 \\
PUIE-AR $_{1}$ & 5.13 & 11.9 & 16.0 & 27.5 & 46.3 & - & 51.7 & 336 \\
PUIE-AR $_{2}$ & 7.04 & 10.0 & 12.9 & 20.5 & 35.3 & 53.0 & 54.6 & 413 \\
PUIE-AR $_{3}$ & 5.01 & 9.61 & 12.8 & 23.3 & 38.8 & 63.1 & 68.8 & 416 \\
\hline
\end{tabular}

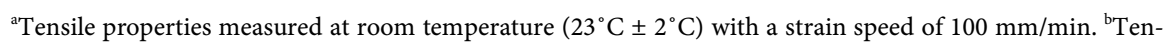
sile strength at breaking point. ${ }^{\circ}$ Elongation at breaking point.
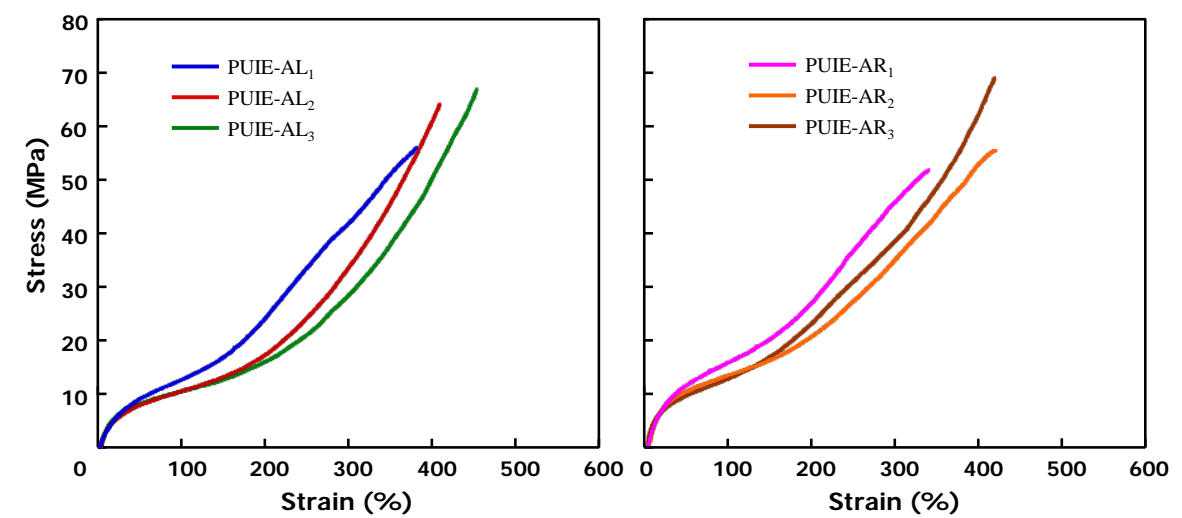

Figure 7. Tensile tests (stress-strain curves) of the PUIEs: blue (PUIE- $\left.\mathrm{AL}_{1}\right)$, red $\left(\mathrm{PUIE}-\mathrm{AL}_{2}\right)$, green $\left(\mathrm{PUIE}-\mathrm{AL}_{3}\right)$, pink $\left(\mathrm{PUIE}-\mathrm{AR}_{1}\right)$, orange $\left(\mathrm{PUIE}-\mathrm{AR}_{2}\right)$, and brown $\left(\mathrm{PUIE}-\mathrm{AR}_{3}\right)$.

the series of PUIE sheets with aliphatic diamine attained even better mechanical properties than PUIE sheets with aromatic diamines, except for the case of PUIE-AR . These results suggest that PUIEs with aliphatic diamines have well-ordered and 
very strong intermolecular hydrogen bonding, whereas PUIEs with aromatic diamines do not allow this. Moreover, the tensile strengths and elongation at break values of PUIEs with aliphatic diamines increased as the molecular length of the diamine increased. The tensile strength of $\mathrm{PUIE}-\mathrm{AR}_{3}$ shows the strongest value (68.8 $\mathrm{MPa})$ in this series of PUIEs. PUIE- $\mathrm{AR}_{3}$ was considered to have better well-ordered packing and stronger intermolecular hydrogen bonding.

\subsection{Thermal Properties}

DSC analyses for the composites were performed over $-120^{\circ} \mathrm{C}$ to $200^{\circ} \mathrm{C}$ under Ar atmosphere. From the data in Table 3, one main transition occurred for the composites. The values for the glass transition temperatures $(\mathrm{Tg})$ of the corresponding PUIEs can be observed in the range between $-60^{\circ} \mathrm{C}$ to $-35^{\circ} \mathrm{C}$. These values were identical to the peak temperature from the E' curves.

The results of DMA analyses for the composites are shown in Figure 8. Modulus-temperature and $\tan \delta$-temperature curves for the PUIEs are provided in Figure 8. The PUIE sheets with aliphatic diamines have almost completely identical thermomechanical behaviors, which show a strong dependence on the imide segment and hydrogen bond strength of the PUIEs. Also, the PUIE sheets with aromatic diamines display a similar behavior. PUIE- $\mathrm{AL}_{1}, \mathrm{PUIE}-\mathrm{AL}_{2}$, and PUIE- $\mathrm{AL}_{3}$ have fairly good rubber integrity plateaus with a modulus of about $3 \times$ $10^{8} \mathrm{~Pa}$. These polymers show movement along the order of their molecular diamine length (PUIE- $\mathrm{AL}_{3}>$ PUIE- $\mathrm{AL}_{2}>\mathrm{PUIE}-\mathrm{AL}_{1}$ ) between $+200^{\circ} \mathrm{C}$ and $+250^{\circ} \mathrm{C}$. PUIE- $\mathrm{AL}_{1}$, PUIE- $\mathrm{AL}_{2}$, and $\mathrm{PUIE}-\mathrm{AL}_{3}$ have a reasonably long rubbery plateau with a modulus of approximately $8 \times 10^{8} \mathrm{~Pa}$. PUIE- $\mathrm{AR}_{1}$ and $\mathrm{PUIE}_{-\mathrm{AR}_{3}}$ start flowing slightly just above $+200^{\circ} \mathrm{C}$. However, PUIE- $\mathrm{AR}_{2}$ starts flowing not more than $+200^{\circ} \mathrm{C}$. This can be explained by the difference in the diamines. These polymers result in well-ordered packing in the imide segments and also form strong intermolecular hydrogen bonding, leading to good microphase separation.

The TGA curves of the PUIEs in Figure 9 and the 5\% and 50\% weight loss temperatures for the PUIEs in Table 3 are reported. As shown in Figure 9, the TGA curves show two distinct stages for decomposition. In the first stage, polyurethane elastomers decomposed slowly until $350^{\circ} \mathrm{C}$, which accounted for the first $5 \%$ of the weight loss. This probably depends on the oxidative degradation of urethane segments (the unstable segments in the composite). In the second stage, weight loss was very rapid in the temperature range of $350^{\circ} \mathrm{C}$ to $500^{\circ} \mathrm{C}$. The formation of PUIEs mainly reduces the mobility of the urethane segment, so the thermal degradation temperature of the composite shifts to higher temperature. The formation of the polyimide hybrid gives a composite with a higher degradation temperature. The main degradation process can be observed at around $440^{\circ} \mathrm{C}$, which is at the $50 \%$ weight loss point. The values of $\mathrm{T}_{5}$ for PUIEs with aliphatic and aromatic diamines were very similar at $345^{\circ} \mathrm{C}-356^{\circ} \mathrm{C}$. However, during the first degradation stage, PUIEs with aromatic diamines degraded more rapidly than PUIEs with aliphatic diamines. 


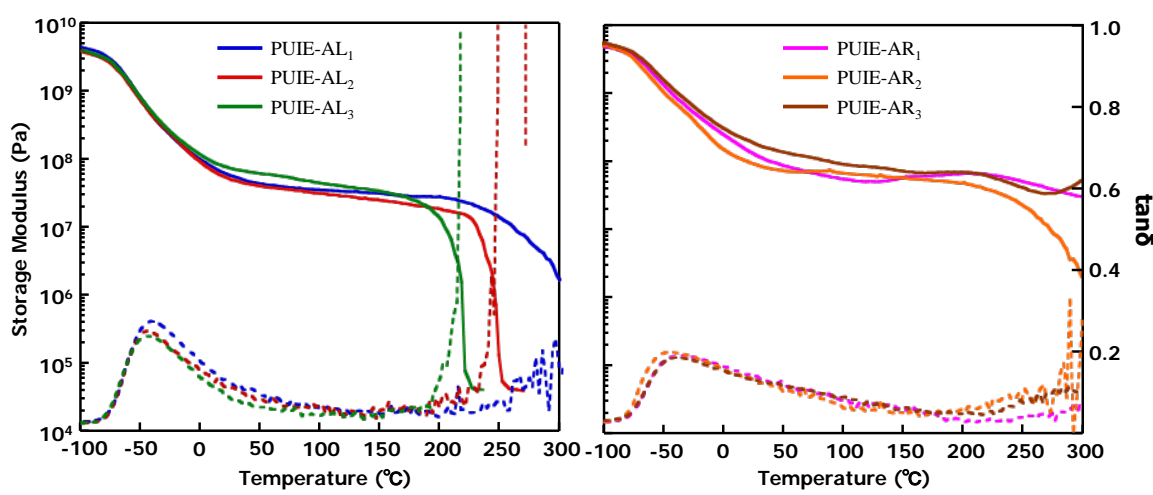

Figure 8. Storage modulus and $\tan \delta$ of the PUIEs as a function of temperature: blue (PUIE- $\left.\mathrm{AL}_{1}\right)$, red $\left(\mathrm{PUIE}-\mathrm{AL}_{2}\right)$, green $\left(\mathrm{PUIE}-\mathrm{AL}_{3}\right)$, pink $\left(\mathrm{PUIE}-\mathrm{AR}_{1}\right)$, orange $\left(\mathrm{PUIE}-\mathrm{AR}_{2}\right)$, and brown (PUIE- $\mathrm{AR}_{3}$ ).

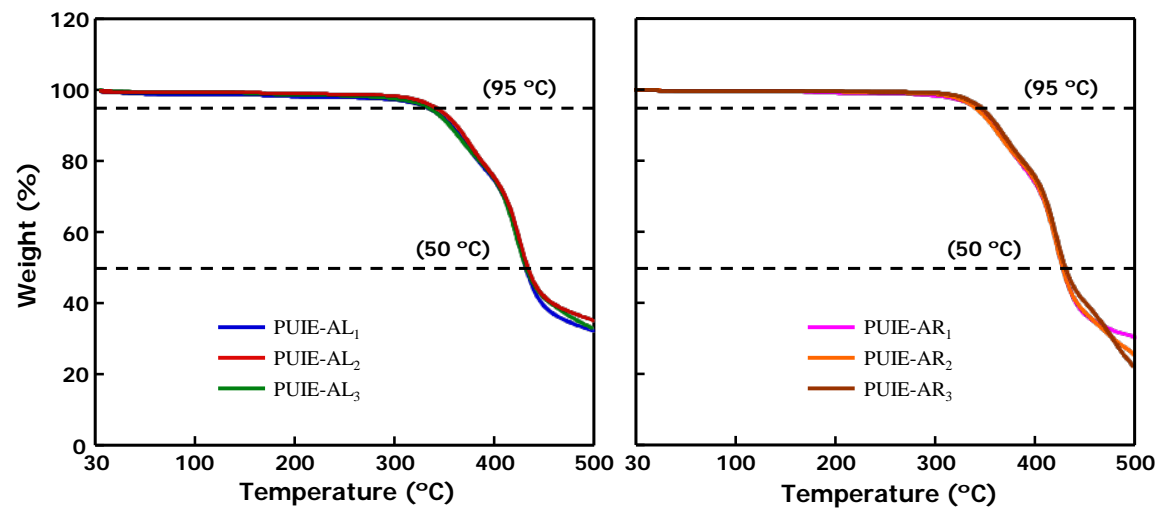

Figure 9. Thermogravimetric analysis (TGA) curves of the PUIEs: blue (PUIE- $\left.A_{1}\right)$, red $\left(\mathrm{PUIE}-\mathrm{AL}_{2}\right)$, green $\left(\mathrm{PUIE}-\mathrm{AL}_{3}\right)$, pink $\left(\mathrm{PUIE}-\mathrm{AR}_{1}\right)$, orange $\left(\mathrm{PUIE}-\mathrm{AR}_{2}\right)$, and brown $\left(\mathrm{PUIE}-\mathrm{AR}_{3}\right)$.

\section{Conclusions}

A series of PUIEs with various diamines were synthesized. The influences of diamine on the chemical, mechanical, and thermal properties, and the surface morphology of the PUIEs were investigated through DSC, DMA, TGA, CA, $\mathrm{AFM}, \mathrm{SEM}$, and XRD. The results prove the existence of diamines in the molecular structure, and the diamines contribute to their morphologies and chemical and physical properties. However, the degree of phase separation is not proportional to the properties of the PUIEs. In addition, the mechanical properties demonstrate that the PUIEs were elastic. Moreover, the moduli of the PUIEs with aliphatic and aromatic diamines increased as the molecular length of the diamine increased. The moduli of PUIEs with DMDA and BAPB are especially high. The cohesive forces between imide segments of PUIEs with aromatic diamines are stronger in comparison with PUIEs with aliphatic diamines. The dynamic, mechanical, and thermal properties suggested that networks between the imide and the urethane segments occurred uniformly in the composites. The properties of the PUIEs had a great influence on the molecular strength or mobility of the diamine contents in the network. However, TGA analyses of PUIEs 
with various diamines did not show any diamine content dependence.

We found that the cohesive forces of the imide segments, which are formed from diamine and pyromellitic dianhydride, had a great influence on the properties of the PUIEs.

\section{Acknowledgements}

The authors are grateful to the ceramic laboratory of AIT for providing access to the X-ray instruments, to Mr. YuzoIshigaki for NMR spectroscopy measurements, and to Mr. Tomohiro Nishio for the dynamic mechanical analysis.

\section{References}

[1] Lin, M.-F., Shu, Y.-C., Tsen, W.-C. and Chuang, F.-S. (1999) Synthesis of Polyurethane-Imide (PU-Imide) Copolymers with Different Dianhydrides and Their Properties. Polymer International, 48, 433-435. https://doi.org/10.1002/(SICI)1097-0126(199906)48:6<433::AID-PI161>3.0.CO;2-1

[2] Asai, K., Inoue, S. and Okamoto H. (2000) Preparation and Properties of Imide-Containing Elastic Polymers from Elastic Polyureas and Pyromellitic Dianhydride. Journal of Polymer Science Part A: Polymer Chemistry, 38, 715-723. https://doi.org/10.1002/(SICI)1099-0518(20000215)38:4<715::AID-POLA6>3.0.CO; $\underline{2-8}$

[3] Takeichi, C., Yamazaki, Y., Fukui, T., Matsumoto, A. and Inagaki, M. (2000) Preparation and Characterization of Porous Carbonized Films by the Pyrolysis of Poly (Urethane-Imide) Films. Tanso, 2000, 388-394. https://doi.org/10.7209/tanso.2000.388

[4] Liu, J. and Ma, D. (2002) Study on Synthesis and Thermal Properties of Polyurethane-Imide Copolymers with Multiple Hard Segments. Journal of Applied Polymer Science, 84, 2206-2215. https://doi.org/10.1002/app.10421

[5] Qiu, F., Yang, D. and Li, P. (2009) Synthesis, Characterization, and Thermos-OpticalProperties of Poly (Urethane-Imide) Based on Azo-Disperse Dye in Its Side Chains. Iranian Polymer Journal, 18, 651-661.

[6] Kogiso, T. and Inoue, S. (2010) Synthesis and Properties of Elastic Polyurethane-Imide. Journal of Applied Polymer Science, 115, 242-248. https://doi.org/10.1002/app.31126

[7] Zang, L., Han, X., Xiao, W. and Li, J. (2011) Synthesis and Property Study of a New Polyurethane-Imide. Hua Gong Jin Zhan, 30, 2491-2494.

[8] Sang, X., Wang, R., Chen, X., Zang, L., An, M. and Shen, Y. (2011) A Review on Synthesis and Property of Polyurethane-Imide. Advanced Materials Research, 284, 1746. https://doi.org/10.4028/www.scientific.net/AMR.284-286.1746

[9] Sang, X., Chen, X., Hou, G. and Yu, S. (2011) Preparation and Properties of RigidPolyurethane-Imide Foams. Advanced Materials Research, 150, 1119.

[10] Wang, Y., Tian, H., Bian, Q., Xiang, A., Ge, X. and Liu, G. (2015) Effect of Trolamine and Dibutyltin Dilaurate on the Structure and Properties of Polyurethane-Imide Foams. Cellular Polymers, 34, 119-135.

[11] Jiang, B., Hao, J., Wang, W., Jiang, L. and Cai, X. (2001) Synthesis and Thermal Properties of Poly (Urethane-Imide). Journal of Applied Polymer Science, 81, 773-781. https://doi.org/10.1002/app.1494

[12] Yeganeh, H. and Shamekli, M.A. (2004) Poly (Urethane-Imide), a New Generation 
of Thermoplastic Elastomers with Enhanced Thermal Stability. Polymer, 45, 359-365.

[13] Gnanasekaran, D. and Reddy, B.S.R. (2011) Synthesis and Characterization of Poly (Urethane-Imide) POSS Nanocomposites. NanoTech Conference \& Expo 2011, 1, 445-448.

[14] Tai, M.-H., Huang, S.-H., Liu, S.-J., Chen, C.-J., Chen, P.-J. and Chen, S.-H. (2008) Synthesis and Properties of Poly(Urethane-Imide) Interpenetrating Network Membranes. Desalination, 233, 191-200.

[15] Zuo, M. and Takeichi, T. (1999) Preparation and Characterization of Poly (Urethane-Imide) Films Prepared from Reactive Polyimide and Polyurethane Prepolymer. Polymer, 40, 5153-5160.

[16] Patel, B.P., Patel, H.S. and Patel, D.B. (2011) Glass Reinforcement of Epoxy Resin Based Poly(Urethane-Imide)S. International Journal of Plastics Technology, 15, 163-173. https://doi.org/10.1007/s12588-012-9021-9

[17] Gui, D., Gao, X., Hao, J. and Liu, J. (2014) Preparation and Characterization of Liquid Crystalline Polyurethane-Imide Modified Epoxy Resin Composites. Polymer Engineering \& Science, 54, 1704-1711. https://doi.org/10.1002/pen.23712 